\title{
Comparative study of laboratory parameters and radiological features in symptomatic and asymptomatic COVID 19 patients
}

\author{
Aaliya Mohi-ud-din Azad ${ }^{1 *}$, Shivani Upadhyay², Saurabh Ojha ${ }^{3}$, Mohd Haris Gulraize Ansari ${ }^{4}$, \\ Mir Shahnawaz ${ }^{5}$, Khurshid Ahmad Dar ${ }^{6}$, Naveed Nazir Shah ${ }^{7}$
}

${ }^{1}$ Senior Resident Doctor, $2,3,4,5$ Post Graduate Trainee, ${ }^{6}$ Professor, ${ }^{7}$ Professor \& HOD, Department of Respiratory Medicine, Government Chest Diseases Hospital, (Government Medical College) Dalgate, Srinagar, Jammu And Kashmir. PIN- 190001, INDIA.

Email: aaliya.azad@gmail.com, shivani@outlook.kr, saurabh.liverpool@gmail.com, mohdharis329@gmail.com, miraasif44@gmail.com, darkhurshid97@gmail.com, naveednazirshah@yahoo.com

\begin{abstract}
Background: Since its first case was reported in December 2019 in Wuhan, China the Corona virus disease 2019 (Covid19) has spread throughout the world leading to a pandemic in 2020. Its presentation can range from mild disease to critical illness and can also be completely asymptomatic. Method: In this study, laboratory parameters and radiological findings of 51 symptomatic and 86 asymptomatic Covid-19 patients, admitted between $24^{\text {th }}$ March 2020 and $10^{\text {th }}$ May 2020 in a tertiary care hospital in Kashmir region of India were analysed. Results: Out of the total 137 patients 86(62.8\%) were asymptomatic (Group A) and 51 (37.2\%) were symptomatic (Group B)..Mean ages in both groups were 37.01 years and 36.87 years respectively with predominance of male gender. Among laboratory parameters leucopenia was present in $5.9 \%$ of asymptomatic patients and $23.5 \%$ of symptomtatic. Lymphopenia was seen in $25.6 \%$ in asymptomatic patients and $37.3 \%$ in symptomatic patients. Thrombocytopenia was seen in $31.4 \%$ of asymptomatic patients and $39.3 \%$ of symptomatic patients. Levels of Serum LDH, CRP, CPK, Serum Ferritin were found higher in symptomatic patients than asymptomatic patients (68.6\% versus $47.7 \%, 27.5 \%$ versus $20.9 \%, 27.5 \%$ versus $18.6 \%, 35.3 \%$ versus $25.6 \%$ respectively). Characteristic CT findings of ground glass opacities with or without consolidation were more likely and extensive in symptomatic patients than in asymptomatic patients (33.3\% versus 6.9\%) Conclusion: Symptomatic patients of Covid 19 were observed to have more deranged laboratory parameters and abnormal CT findings as compared to asymptomatic patients.

Key Words: COVID 19, Asymptomatic Respiratory Infection, Biochemical Markers, Lung Radiology
\end{abstract}

*Address for Correspondence:

Dr Aaliya Mohi-ud-din Azad, Senior Resident Doctor, Department of Respiratory Medicine, Government Chest Diseases Hospital (Government Medical College), Dalgate, Srinagar, Jammu And Kashmir, India. PIN- 190001, 91-7838442225, INDIA.

Email: aaliya.azad@gmail.com

Received Date: 24/09/2020 Revised Date: 02/10/2020 Accepted Date: 14/10/2020

DOI: https://doi.org/10.26611/10211631

This work is licensed under a Creative Commons Attribution-NonCommercial 4.0 International License. (cc)) EY-NC

\begin{tabular}{|l|l|}
\hline \multicolumn{2}{|c|}{ Access this article online } \\
\hline Quick Response Code: & Website: \\
& www.medpulse.in \\
& \\
& \\
\hline
\end{tabular}

\section{INTRODUCTION}

The first case of COVID 19 was reported in Wuhan city in the Hubei province of China in 2019. Since then Covid 19 has spread throughout the world involving all continents except Antarctica. The World Health Organisation (WHO) declared COVID 19 a pandemic on March 11, 2019 ${ }^{1}$. The causing agent, the Novel Coronavirus, was identified to be an enveloped non segmented positive sense RNA virus belonging to the family Coronaviridae and shared similarities with the Severe Acute Respiratory Syndrome Corona virus (SARS-CoV) and Middle East Respiratory Syndrome Corona virus (MERS-CoV) ${ }^{2-4}$ The virus is primarily transmitted between people through respiratory droplets and direct and indirect contact routes. 
Transmission can also occur through fomites in the immediate environment around the infected person (e.g., stethoscope or thermometer $)^{5}$. Presentation varies from mild to severe disease, to critical illness. Most patients present with mild respiratory symptoms and may not require any treatment. Elderly and those with underlying comorbidities such as cardiovascular disease, diabetes, chronic respiratory disease, and cancer are more likely to develop serious illness. The most common symptoms are fever and cough in addition to other symptoms such as breathlessness, sore throat, head ache, fatigue, diarrhea, and haemoptysis ${ }^{6}$. The diagnosis is made by detecting viral RNA through real time reverse transcriptase polymerase chain reaction (rRT-PCR) present in respiratory secretions obtained through oropharyngeal or nasopharyngeal swab, endobronchial aspirate or bronchoalveolar lavage. Computed Tomography of chest shows bilateral peripheral focal or multifocal ground glass opacities. In later stages it shows crazy paving and consolidation ${ }^{7}$. Laboratory parameters such as complete blood count, haemoglobin, serum lactate dehydrogenase, serum ferretin, C- reactive protein, creatine kinase play an important role in determining prognosis of the patients especially in critically ill patients. $^{8}$

\section{MATERIALS AND METHOD}

Study population and design

The retrospective cohort study was approved by the institutional review board. Informed consent for this study was waived by the ethics committee of our institute in view of emerging infectious disease. For this single centre study, we recruited 140 rRT-PCR confirmed COVID 19 admitted between $24^{\text {th }}$ March 2020 and $10^{\text {th }}$ May 2020 in a tertiary centre dedicated for COVID 19. The patients were divided in two groups based on symptomatic history. Group A had 86 asymptomatic patients and Group B included 51 symptomatic patients. On the same day of admission blood investigations were sent under all aseptic precautions and all patients underwent chest CT within 48 hours of admission.

Procedure

The information noted included demographics, medical history, exposure history, co morbidities, symptoms, signs, laboratory results, chest X-ray and chest computed tomographic scans (CT). Laboratory assessment consisted of complete blood count, liver and renal functions, lactate dehydrogenase, C-reactive protein, creatine kinase, serum ferritin and Procalcitonin. The biochemical tests were performed on Thermofischer Scientific clinical chemistry analyser, Finland (Type 803). CBC was done on Cobasautomatic analyser. The consultant radiologist documented the radiological findings on a preformed proforma which was later analysed by two attending pulmonologists.

Study definition

Symptomatic COVID 19 case is a case who has developed signs and symptoms compatible with COVID 19 viral infection such as fever (temperature $>37.5^{\circ} \mathrm{C}$ ), cough and dyspnoea [9].

Asymptomatic COVID 19 case is defined as a laboratory confirmed COVID 19 infected case that does not develop any symptom ${ }^{9}$.

Anemia was defined as haemoglobin $<13 \mathrm{gm} \%$ in males and $<12$ gm $\%$ in females $^{10}$.

Leucocytopenia was defined total leucocyte count $<4000$ cells $/ \mathrm{mm} 3^{11}$.

Lymphocytopenia was defined as absolute lymphocyte count $<1500$ cells $/ \mathrm{mm}^{11}$.

Thrombocytopenia was defined as platelet count $<150000$ $/ \mathrm{mm} 3^{11}$.

Tranaminitis was defined as AST and/or ALT levels $>40$ Units/L $\mathrm{L}^{12}$.

Clinical data and variables assessed

We obtained demographic data; clinical history on the day of admission; laboratory and radiological results were obtained within 24 and 48 hours of admission respectively. Data was tabulated and analysed.

Statistical analysis

Data was keyed into MS Excel and imported to the statistical software. Categorical variables were summarised as counts and percentages. Continuous variables were expressed as medians and simple ranges. No assertion was made for missing data. Chi-square test or Fisher's exact test were used to compare differences between categorical variables as appropriate. Means for continuous variables were compared by independent group $\mathrm{t}$-tests or Kolmogorov-Smirnov test as appropriate. A twosided $\alpha$ of less than 0.05 was considered statistically significant. All statistical analyses were performed using SPSS (Statistical Package for the Social Sciences) version 25.0 software.

\section{OBSERVATIONS AND RESULTS}

Of the 137 patients with COVID 19 hospitalised at one tertiary care hospital from $24^{\text {th }}$ March 2020 and $10^{\text {th }}$ May 2020 patients $86(62.8 \%)$ were asymptomatic (Group A) and 51 (37.2\%) were symptomatic (Group B). Demographic characteristics, clinical characteristics and underlying co-morbidities are shown in Table 1. 
Table 1: Demographic characteristics, clinical characteristics and underlying co-morbidities

\begin{tabular}{|c|c|c|c|c|c|}
\hline & & \multicolumn{2}{|c|}{ GROUP A Asymptomatic $(n=86)$} & \multicolumn{2}{|c|}{ GROUP B Symptomatic $(n=51)$} \\
\hline & & Count & Column N \% & Count & Column N \% \\
\hline Age & $<=10.0$ & 3 & $3.5 \%$ & 4 & $7.8 \%$ \\
\hline \multirow[t]{7}{*}{ (Binned) } & $11.0-20.0$ & 13 & $15.1 \%$ & 10 & $19.6 \%$ \\
\hline & $21.0-30.0$ & 23 & $26.7 \%$ & 10 & $19.6 \%$ \\
\hline & $31.0-40.0$ & 16 & $18.6 \%$ & 9 & $17.6 \%$ \\
\hline & $41.0-50.0$ & 15 & $17.4 \%$ & 2 & $3.9 \%$ \\
\hline & $51.0-60.0$ & 4 & $4.7 \%$ & 9 & $17.6 \%$ \\
\hline & $61.0-70.0$ & 10 & $11.6 \%$ & 6 & $11.8 \%$ \\
\hline & $>70.0$ & 2 & $2.3 \%$ & 1 & $2.0 \%$ \\
\hline \multirow[t]{2}{*}{ Gender } & Male & 49 & $57.0 \%$ & 35 & $68.6 \%$ \\
\hline & Female & 37 & $43.0 \%$ & 16 & $31.4 \%$ \\
\hline \multirow[t]{13}{*}{ Symptoms } & Dry cough & - & - & 25 & $49.0 \%$ \\
\hline & Fever & - & - & 24 & $47.0 \%$ \\
\hline & Myalgia & - & - & 15 & $29.4 \%$ \\
\hline & Sore throat & - & - & 13 & $25.5 \%$ \\
\hline & Rhinorrhoea & - & - & 13 & $25.5 \%$ \\
\hline & Anorexia & - & - & 11 & $21.6 \%$ \\
\hline & Fatigue & - & - & 10 & $19.6 \%$ \\
\hline & Dyspnoea & - & - & 7 & $13.7 \%$ \\
\hline & Anosmia & - & - & 6 & $11.8 \%$ \\
\hline & Dysgeusia & - & - & 5 & $9.8 \%$ \\
\hline & Headache & - & - & 5 & $9.8 \%$ \\
\hline & Diarrhoea & - & - & 2 & $3.9 \%$ \\
\hline & Hemoptysis & - & - & 2 & $3.9 \%$ \\
\hline \multicolumn{2}{|c|}{ Underlying co-morbidities } & 9 & $10.4 \%$ & 15 & $29.4 \%$ \\
\hline \multicolumn{2}{|c|}{ COPD } & 1 & $1.2 \%$ & 3 & $5.9 \%$ \\
\hline \multicolumn{2}{|c|}{ Asthma } & 0 & $0.0 \%$ & 1 & $2.0 \%$ \\
\hline \multicolumn{2}{|c|}{ Diabetes } & 3 & $3.5 \%$ & 3 & $5.9 \%$ \\
\hline \multicolumn{2}{|c|}{ CAD } & 1 & $1.2 \%$ & 1 & $2.0 \%$ \\
\hline \multicolumn{2}{|c|}{ CKD } & 1 & $1.2 \%$ & 2 & $3.9 \%$ \\
\hline \multicolumn{2}{|c|}{ Cancer } & 0 & $0.0 \%$ & 1 & $2.0 \%$ \\
\hline \multicolumn{2}{|c|}{ Hypertension } & 7 & $8.1 \%$ & 8 & $15.7 \%$ \\
\hline \multicolumn{2}{|c|}{ Cerebrovascular Disease } & 0 & $0.0 \%$ & 2 & $3.9 \%$ \\
\hline \multicolumn{2}{|c|}{ Thyroid Disease } & 4 & $4.7 \%$ & 2 & $3.9 \%$ \\
\hline \multicolumn{2}{|c|}{ OSA } & 0 & $0.0 \%$ & 1 & $2.0 \%$ \\
\hline \multicolumn{2}{|c|}{ Active Smokers } & 13 & $15.1 \%$ & 18 & $35.3 \%$ \\
\hline \multicolumn{2}{|c|}{ Reformed Smokers } & 8 & $9.3 \%$ & 12 & $23.5 \%$ \\
\hline
\end{tabular}

Mean age of patients in Group A was 37.01 years ( \pm SD 17.16) with median age of 35 years. 49 (57.0\%) were males and 37 (43\%) were females. Mean age of patients in Group B was 36.69 years $( \pm 20.16)$ with median age of 32 years. $35(68.6 \%)$ were males and $16(31.4 \%)$ were females. In Group B most common symptoms were dry cough (49\%), fever (47\%), myalgia (29.4\%). Sore throat and rhinorrhoea were present in $25.5 \%$ patients each. Anorexia (21.6\%), fatigue (19.6\%), dyspnoea (13.7), anosmia $(11.8 \%)$, dysguesia $(9.8 \%)$, headache $(9.8 \%)$ was also common symptoms at presentation. Diarrhoea (3.9\%) and haemoptysis (3.9\%) were also seen. In Group A, 9 (10.4\%) patients had known underlying co-morbidities. Hypertension, present in 7 (8.1\%) patients, was most common co-morbidity. 4 patients $(4.7 \%)$ had thyroid dysfunction, $3(3.5 \%)$ were diabetics on treatment. Chronic obstructive pulmonary disease, coronary artery disease, and chronic kidney disease were present in 1 patient (1.2\%) each. $13(15.1 \%)$ patients were active smokers and 8 (9.3\%) were reformed smokers. In Group B, 15(29.4\%) patients had known underlying co-morbidities. Hypertension, present in $8(15.7 \%)$ was most common co-morbidity. Diabetes Mellitus was present in 3 patients $(5.9 \%)$.Thyroid dysfunction, cerebrovascular disease and chronic kidney Disease were present in 2 patients $(3.9 \%)$ each. Bronchial Asthma, Coronary artery disease, malignancy and obstructive sleep apnoea were present in 1 patient (2.0\%) each .18 patients $(35.3 \%)$ were active smokers and $12(23.5 \%)$ patients were reformed smokers. Table-2 shows laboratory and radiographic findings of all patients. In Group A leucopoenia was seen in $5(5.8 \%)$ patients, Lymphopenia was seen in $22(25.8 \%)$ patients. Thrombocytopenia was present in $27(31.4 \%)$ patients. Serum creatinine was raised in $7(8.1 \%)$ patients. Transaminitis was seen in $32(37.2 \%)$ patients among which raised AST was found in $21(24.4 \%)$ and raised ALT was found In 31 (36.0\%) patients. ALP was found elevated $(>150 \mathrm{U} / \mathrm{L})$ in $54(62.8 \%)$ patients. Elevated LDH (>250U/L) was found in $41(47.7 \%)$. 
Table 2: Laboratory and radiographic findings

\begin{tabular}{cccc}
\hline & GROUP A & GROUP B & p-value \\
& Asymptomatic (n=86) & $\begin{array}{c}\text { Symptomatic (n=51) } \\
\text { Laboratory findings }\end{array}$ & \\
Anaemia & $19(22.1 \%)$ & $8(15.7 \%)$ & 0.386 \\
WBC $<4000$ & $5(5.8 \%)$ & $12(23.5 \%)$ & 0.003 \\
Lymphocytes $<1500$ & $22(25.6 \%)$ & $19(37.3 \%)$ & 0.178 \\
Platelets $<1.5$ & $27(31.4 \%)$ & $20(39.2 \%)$ & 0.359 \\
CRT>1.4 & $7(8.1 \%)$ & $6(11.8 \%)$ & 0.552 \\
Sugar $>120$ & $3(3.5 \%)$ & $3(5.9 \%)$ & 0.671 \\
SGOT>40 & $21(24.4 \%)$ & $14(27.5 \%)$ & 0.84 \\
SGPT>40 & $31(36.0 \%)$ & $20(39.2 \%)$ & 0.719 \\
ALP $>150$ & $54(62.8 \%)$ & $38(74.5 \%)$ & $>0.999$ \\
LDH>250 & $41(47.7 \%)$ & $35(68.6 \%)$ & 0.021 \\
CRP $>10$ & $18(20.9 \%)$ & $14(27.5 \%)$ & 0.409 \\
CK $>170$ & $16(18.6 \%)$ & $14(27.5 \%)$ & 0.286 \\
Ferritin>300 & $22(25.6 \%)$ & $18(35.3 \%)$ & 0.248 \\
& Radiographic findings & & \\
Abnormalities on Chest CT & $7(8.1 \%)$ & $17(33.3 \%)$ & $<0.001$ \\
GGO & $5(5.8 \%)$ & $15(29.4 \%)$ & $<0.001$ \\
Consolidation & $3(3.5 \%)$ & $11(21.6 \%)$ & 0.001 \\
\hline
\end{tabular}

Raised CRP (>10 mg/L) was found in 18 (20.9\%). Raised CK $(>170 \mathrm{U} / \mathrm{L})$ was seen in $16(18.6 \%)$ patients. Elevated Ferretin $(>300 \mathrm{ng} / \mathrm{ml})$ was found in $22(25.6 \%)$ patients. In Group B leucopoenia was seen in $12(23.5 \%)$ patients, Lymphopenia was seen in $19(37.3 \%)$ patients. Thrombocytopenia was present in $20(39.2 \%)$ patients. Serum creatinine was raised in $6(11.8 \%)$ patients. Transaminitis was seen in $23(45.1 \%)$ patients among which raised AST was found in $14(27.5 \%)$ and raised ALT was found In 20 (39.2\%) patients. ALP was found elevated $(>150 \mathrm{U} / \mathrm{L})$ in $38(74.5 \%)$ patients. Elevated LDH $(>250 \mathrm{U} / \mathrm{L})$ was found in $35(68.6 \%)$. Raised CRP $(>10$ $\mathrm{mg} / \mathrm{L})$ was found in 14 (27.5\%). Raised CK (>170 U/L) was seen in $14(27.5 \%)$ patients. Elevated ferretin ( $>300$ $\mathrm{ng} / \mathrm{ml})$ was found in $18(35.3 \%)$ patients. Abnormalities in chest radiograph in Group A and Group B were seen in 7 (8.1\%) and 17 (33.3\%) patients respectively. In Group A ground glass opacities were seen in $5(5.8 \%)$ and consolidations in 3(3.5\%) patients. In Group B 15 (29.4\%) patients had GGOs and 11 (21.6\%) had consolidation.

\section{DISCUSSION}

COVID 19 is caused by the novel corona virus which shares similarities to SARS-CoV and MERS- CoV. It was not a known human pathogen before the 2019 pandemic. Patients suffer from mild respiratory illness with flu-like symptoms to severe to critical illness requiring ventilator support. . In severe cases, dyspnoea, respiratory distress, or septic shock may occur, develop into severe disease, or even result in death. Most COVID -19 patients present with mild illness. However, many patients do not develop any symptom throughout the course of infection. It is a highly contagious disease. Asymptomatic patients can go undetected and be responsible for spreading it. In the nasal cavity the inhaled virus SARS-CoV-2 likely binds to epithelial cells via mainly the ACE2 receptors and starts replicating ${ }^{13,14}$. In the conducting airways the ciliated cells are primary cells infected ${ }^{15}$. There is local propagation of the virus but a limited innate immune response. In asymptomatic patients the viral burden may be low, these individuals are infectious. In our study, we compiled, tabulated and analysed data of 137 COVID-19 patients admitted in a tertiary care hospital from 24th March 2020 and 10th May 2020. Patients were divided in 2 groups based on presence and absence of symptoms. In Group A 86 asymptomatic patients were included and Group B had 51 symptomatic patients. Both groups had males were in predominance, as has been found in other previous studies done in COVID-19 patients ${ }^{16,17}$. X chromosome and sex hormones play an important role in innate and adaptive immunity which may be a reason; fewer females are contracting the disease ${ }^{18,19}$. In Group A $26.7 \%$ patients belonged to the age group of 21-30 years and $18.6 \%$ belonged to the age group of $31-40$ years. In Group B $19.6 \%$ belonged to the age groups of 11-20 years and 2130 years each. Among the symptomatic patients dry cough (49\%) was found to be the most common symptom followed by fever (47.0\%). In other studies fever was most common symptom followed by dry cough ${ }^{16,17}$. Other common symptoms were myalgia $(29.4 \%)$, sore throat $(25.5 \%)$, rhinorrhoea $(25.5 \%)$, anorexia $(21.6 \%)$, fatigue (19.6\%), dyspnoea (13.7\%), anosmia (11.8\%), dysgeusia(9.8\%), headache (9.8\%). Haemoptysis $(3.9 \%)$ and diarrhoea (3.9\%) were the least common symptoms. Patients experience upper respiratory symptoms and gastrointestinal symptoms as the target receptors ACE2 
and TMPRSS2 are located in upper respiratory epithelium and gut epithelium [20]. Upper respiratory symptoms are more common as expression of viral receptors/entryassociated proteins is skewed towards the upper airway which may also correlate with enhanced transmissivity ${ }^{20} \mathrm{In}$ Group A $10.4 \%$ patients had underlying diseases including hypertension $(8.1 \%)$, thyroid dysfunction $(4.7 \%)$, diabetes (3.5\%), COPD (1.2\%), CAD (1.2\%), CKD (1.2\%). In Group B $29.4 \%$ patients had underlying diseases including hypertension (15.7\%), diabetes (5.9\%), COPD (5.9\%), thyroid dysfunction $(3.9 \%)$, cerebrovascular diseases $(3.9 \%)$, CKD (3.9\%), CAD (2.0\%), OSA (2.0\%), Asthma $(2.0 \%)$, and malignancy $(2.0 \%)$. Our results suggest that presence of any coexisting illness was more common among symptomatic patients. Other studies also suggest that coexisting illnesses predisposed COVID 19 patients to develop severe disease ${ }^{11} 15.1 \%$ were active smokers and 9.3\% were reformed smokers in Group A. 35.3\% were active smokers and $23.5 \%$ were reformed smokers in Group B. Tobacco smoke exposure results in inflammatory processes in the lung, increased mucosal inflammation, expression of inflammatory cytokines and tumor necrosis factor $\alpha$, increased permeability in epithelial cells, mucus overproduction, and impaired mucociliary clearance ${ }^{22}$. Laboratory findings in Group A and Group B were leucocytopenia in $5(5.8 \%)$ and $12(23.5 \%)$ patients, lymphocytopenia in $22(25.6 \%)$ and $19(37.7 \%)$, thrombocytopenia in $27(31.4 \%)$ and $20(39.2 \%)$, serum creatinine was raised in $7(8.1 \%)$ and $6(11.8 \%)$ patients respectively. Blood sugars were raised in $3(3.5 \%)$ patients in Group A and $3(5.9 \%)$ patients in Group B. Transaminitis was present in 31 (36.0\%) patients in Group A and $23(45.0 \%)$ in Group B. SGOT was raised in $21(24.4 \%)$ and $14(27.5 \%)$ patients in group A and B respectively. SGPT was raised in $31(36.0 \%)$ and 20 (39.2\%) patients respectively. ALP was raised in 54 $(62.8 \%)$ patients in Group A and $38(74.5 \%)$ in Group B. Raised LDH levels were seen in $41(47.7 \%)$ patients and $35(68.6 \%)$ patients respectively. CRP was raised in 18 (20.9\%) and 14 (27.5\%) patients respectively. Raised CK was found in $16(18.6 \%)$ patients and $14(27.5 \%)$, serum procalcitonin was raised in $2(2.3 \%)$ and $2(3.9 \%)$ patients, serum ferretin was raised in $22(25.6 \%)$ and $18(35.3 \%)$ patients in Group A and Group B respectively. Significant difference among laboratory parameters in Group A and Group B was found in leucocytopenia (p-value 0.003) and Serum LDH levels (p-value 0.021). However ALP, CK, CRP, LDH and Ferretin were found raised in both groups. Other studies have found elevated levels of these parameters correlate with severity of the disease. However in our study we have found no significant difference between these parameters in asymptomatic and symptomatic cases of COVID 19 except serum LDH levels. Abnormalities in chest radiograph in Group A and Group B were seen in 7 (8.1\%) and 17 (33.3\%) patients respectively. In Group A ground glass opacities were seen in $5(5.8 \%)$ and consolidations in $3(3.5 \%)$ patients. In Group B 15 (29.4\%) patients had GGOs and 11 (21.6\%) had consolidation. The most common characteristics of COVID-19 on CT images are ground-glass opacity with consolidation, pure ground-glass opacity, with a peripheral distribution. Symptomatic patients are more likely to have CT findings as compared to asymptomatic patients. These characteristics have been found to be related to the progress and prognosis of disease in various studies ${ }^{11,23}$.

\section{CONCLUSION}

In our single centre study of 137 patients admitted in a tertiary care hospital, majority of the patients were young, males, asymptomatic to mildly symptomatic, with a good clinical outcome. Most common symptoms were dry cough followed by fever. Symptomatic patients were more likely to have underlying co morbidities. Among laboratory parameters significant difference was found in leucocytopenia and serum LDH. Symptomatic patients had characteristic findings of peripheral ground glass opacities and consolidations. However asymptomatic patients also had CT findings in lungs and therefore should undergo radiological investigations to rule out lung involvement which can change their management.

\section{REFERENCES}

1. WHO Rolling updates on Coronavius Disease 2019 (COVID

https://www.who.int/emergencies/diseases/novelcoronavirus-2019/events-as-they-happen

2. Richman DD, Whitley RJ, Hayden FG, eds. Clinical virology, 4th edn. Washington: ASM Press, 2016.

3. Ksiazek TG, Erdman D, Goldsmith CS, et al.. A novel coronavirus associated with severe acute respiratory syndrome. N Engl J Med 2003; 348: 1953-66.

4. Kuiken T, Fouchier RAM, Schutten M, et al.. Newly discovered coronavirus as the primary cause of severe acute respiratory syndrome. Lancet $2003 ; 362$ : 263-70

5. WHO Modes of transmission of virus causing COVID-19 implications for IPC precaution recommendations https://www.who.int/news-

room/commentaries/detail/modes-of-transmission-ofvirus-causing-covid-19-implications-for-ipc-precautionrecommendations

6. Wang W, Tang J, Wei F. Updated understanding of the outbreak of 2019 novel coronavirus $(2019-\mathrm{nCoV})$ in Wuhan, China. J Med Virol 2020 January 29 (Epub ahead of print), doi: 10.1002/jmv.25689.

7. Jeffrey P. Kanne, Brent P. Little et al..Essentials for Radiologists on COVID-19: An UpdateRadiology Scientific Expert Panel, https://doi.org/10.1148/radiol.2020200527

8. Evangelos Terpos et al.. Hematological findings and complications of COVID -19 published 13 April 
2020American journal of haematology https://doi.org/10.1002/ajh.25829

9. World Health Organization. ((2020 Coronavirus disease . 2019 (COVID-19) : situation report, 73. World Health .Organizationhttps://apps.who.int/iris/handle/10665/3316 86

10. Anemia in Clinical Practice-Definition and Classification: Does Hemoglobin Change With Aging? https://www.sciencedirect.com/science/article/abs/pii/S00 37196315000621?via\%3Dihub .

11. Wei-jie Guan et al. Clinical Characteristics of Coronavirus Disease 2019 in China published April 30, 2020 Engl J Med 2020; 382:1708-1720 DOI: 10.1056/NEJMoa2002032

12. Ch. Evaluation of Liver function,Harrison's principles of internal medicine $20^{\text {th }}$ edition

13. Wan Y, Shang J, Graham R, et al.. Receptor recognition by novel coronavirus from Wuhan: An analysis based on decade-long structural studies of SARS. J Virol 2020; 94: e00127-20.

14. Hoffmann M, Kleine-Weber H, Schroeder S, et al.. SARS-CoV-2 cell entry depends on ACE2 and TMPRSS 2 and is blocked by a clinically proven protease inhibitor. Cell 2020; in press https://doi.org/10.1016/j.cell.2020.02.052

15. Sims AC, Baric RS, Yount B, et al..Severe acute respiratory syndrome coronavirus infection of human ciliated airway epithelia: role of ciliated cells in viral spread in the conducting airways of the lungs. $J$ Virol 2005; 79: 15511-15524. doi:10.1128/JVI.79.24.15511-15524.2005

16. Huang $\mathrm{C}$, Wang $\mathrm{Y}$, Li $\mathrm{X}$, et al.. Clinical features of patients infected with 2019 novel coronavirus in Wuhan, China. Lancet. 2020. Doi: 10.1016/s0140-6736(20)301835 .
17. Heshui Shi, MD Radiological findings from 81 patients with COVID-19 pneumonia in Wuhan, China: a descriptive study Published:February 24, Lancet. 2020DOI:https://doi.org/10.1016/S1473-3099(20)300864

18. Sébastien Jaillon 12 , Kevin Berthenet 3, Cecilia Garlanda 4 Sexual Dimorphism in Innate Immunity DOI: $10.1007 / \mathrm{s} 12016-017-8648-\mathrm{x}$

19. Prof Nanshan Chen, MD Epidemiological and clinical characteristics of 99 cases of 2019 novel coronavirus pneumonia in Wuhan, China: a descriptive study, Lancet Published:January 30 , 2020DOI:https://doi.org/10.1016/S0140-6736(20)302117

20. Sungnak, W., Huang, N., Bécavin, C. et al.. SARS-CoV-2 entry factors are highly expressed in nasal epithelial cells together with innate immune genes. Nat Med 26, 681-687 (2020). https://doi.org/10.1038/s41591-020-0868-6

21. Dryden M, Baguneid M, Eckmann $\mathrm{C}$ et al.. Pathophysiology and burden of infection in patients with diabetes mellitus and peripheral vascular disease: focus on skin and soft-tissue infections. Clin Microbiol Infect. 2015; 21: S27-S32

22. Strzelak, A.; Ratajczak, A.; Adamiec, A.; Feleszko, W. Tobacco Smoke Induces and Alters Immune Responses in the Lung Triggering Inflammation, Allergy, Asthma and Other Lung Diseases: A Mechanistic Review. Int. J. Environ. Res. Public Health 2018, 15, 1033.

23. Tingting Zhu, Yujin Wang, Shuchang Zhou, Na Zhang, Liming XiaA Comparative Study of Chest Computed Tomography Features in Young and Older Adults With Corona Virus Disease (COVID-19)J Thorac Imaging. $2020 \quad$ Mar 31: 10.1097/RTI.0000000000000513. Published online 2020 Mar 31. doi: 10.1097/RTI.0000000000000513. PMCID: PMC7253040.

$$
\begin{aligned}
& \text { Source of Support: None Declared } \\
& \text { Conflict of Interest: None Declared }
\end{aligned}
$$

